\title{
Ketamine's Effects on the Glutamatergic and GABAergic Systems: A Proteomics and Metabolomics Study in Mice
}

\author{
Katja Weckmann ${ }^{a}{ }^{f}$ Michael J. Deery ${ }^{b}$ Julie A. Howard ${ }^{b}$ Renata Feret ${ }^{b}$ \\ John M. Asara ${ }^{C}$ Frederik Dethloff $^{a}$ Michaela D. Filiou $^{d}$ Christiana Labermaier $^{\mathrm{a}}$ \\ Giuseppina Maccarrone $^{a}$ Kathryn S. Lilley ${ }^{b}$ Marianne Mueller $^{\mathrm{e}}$ \\ Christoph W. Turck ${ }^{a}$
}

\begin{abstract}
a Max Planck Institute of Psychiatry, Department of Translational Research in Psychiatry, Munich, Germany;
${ }^{b}$ Cambridge Centre for Proteomics, Cambridge System Biology Centre, University of Cambridge, Cambridge, UK;

'Division of Signal Transduction, Beth Israel Deaconess Medical Center and Department of Medicine, Harvard Medical School, Boston, MA, USA; d Department of Biological Applications and Technology, School of Health

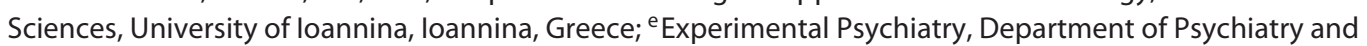
Psychotherapy and Focus Program Translational Neuroscience, Johannes Gutenberg University Medical Center, Mainz, Germany; ${ }^{\mathrm{f} I n s t i t u t e}$ for Pathobiochemistry, University Medical Center of the Johannes Gutenberg University Mainz, Mainz, Germany
\end{abstract}

\section{Keywords}

Ketamine - Metabolomics · Gamma-aminobutyric acid .

Glutamate $\cdot$ Proteomics

\begin{abstract}
Ketamine, a noncompetitive, voltage-dependent N-MethylD-aspartate receptor (NMDAR) antagonist, has been shown to have a rapid antidepressant effect and is used for patients experiencing treatment-resistant depression. We carried out a time-dependent targeted mass spectrometry-based metabolomics profiling analysis combined with a quantitative based on in vivo ${ }^{15} \mathrm{~N}$ metabolic labeling proteome comparison of ketamine- and vehicle-treated mice. The metabolomics and proteomics datasets were used to further elucidate ketamine's mode of action on the gamma-aminobutyric acid
\end{abstract}

\section{KARGER}

(c) 2018 S. Karger AG, Basel

E-Mail karger@karger.com

www.karger.com/mnp
(GABA)ergic and glutamatergic systems. In addition, myelin basic protein levels were analyzed by Western Blot. We found altered GABA, glutamate and glutamine metabolite levels and ratios as well as increased levels of putrescine and serine - 2 positive modulators of the NMDAR. In addition, GABA receptor (GABAR) protein levels were reduced, whereas the alpha-amino-3-hydroxy-5-methyl-4-isoxazolepropionic acid receptor (AMPAR) subunit Gria2 protein levels were increased upon ketamine treatment. The significantly altered metabolite and protein levels further significantly correlated with the antidepressant-like behavior, which was assessed using the forced swim test. In conclusion and in line with previous research, our data indicate that ketamine impacts the AMPAR subunit Gria2 and results in decreased GABAergic inhibitory neurotransmission leading to increased excitatory neuronal activity.

(c) 2018 S. Karger AG, Basel 


\section{Introduction}

In 2000, Berman et al. [1] demonstrated for the first time a rapid antidepressant effect of a low dose of ketamine, 2 and $4 \mathrm{~h}$ after administration of the drug and this effect lasted up to 10 days. Ketamine, a drug usually used for anesthesia, is a noncompetitive, voltage-dependent, $\mathrm{N}$ Methyl-D-aspartate receptor (NMDAR) antagonist that equally blocks the NMDAR subtype $2 \mathrm{~A}$ - and $2 \mathrm{~B}$-containing receptors in the presence of $\mathrm{Mg}^{2+}$ [2-7]. An antidepressant effect of ketamine is observed in patients experiencing treatment-resistant depression $[8,9]$. Moreover, ketamine diminishes suicidal ideation [10]. Ketamine is not used as a first-line drug due to its psychomimetic side effects [1113]. The fact that ketamine is an NMDAR antagonist suggests that the glutamatergic system of the brain including receptors, modulators, and associated pathways is tightly linked to its mechanism of action. Ketamine's antidepressant activity results from its action on the gamma-aminobutyric acid (GABA)ergic and glutamatergic systems. Synaptic plasticity, especially long-term potentiation (LTP), is promoted by glutamate that is released into the synaptic cleft upon neuronal activity. Once released, glutamate binds and activates alpha-amino-3-hydroxy-5-methyl4-isoxazolepropionic acid receptors (AMPARs) and NMDARs. In contrast, GABA release into the synaptic cleft by GABAergic inhibitory interneurons inhibits neuronal activity and synaptic plasticity. Glutamine is metabolized to glutamate and GABA in neurons [14-17].

A low dose of ketamine ( 5 and $10 \mathrm{mg} \mathrm{kg}^{-1}$ ) seems to act through the activation of a mammalian target of rapamycin and has been shown to cause an increased expression of synaptic proteins including postsynaptic density protein-95, synapsin 1 , and the AMPAR subunit Grial in the medial prefrontal cortex of rats $\left(10 \mathrm{mg} \mathrm{kg}^{-1}\right.$ of ketamine) and AMPAR subunits Gria1 and Gria2 levels in the hippocampus of mice ( $10 \mathrm{mg} \mathrm{kg}^{-1}$ of ketamine). Moreover, an elevated number of spines and spine activity in the medial prefrontal cortex of rats $\left(10 \mathrm{mg} \mathrm{kg}^{-1}\right.$ of ketamine) have been observed in response to the drug $[18,19]$. Ketamine's antidepressant-like effects are dependent on AMPARs. Blocking AMPARs with 2,3-Dihydroxy-6-nitro-7-sulfamoyl-benzochinoxaline-2,3-dione (NBQX) reverses the antidepressant-like behavioral effects in mice ( $3 \mathrm{mg} \mathrm{kg}^{-1}$ of ketamine) and rats (10 mg $\mathrm{kg}^{-1}$ of ketamine) $[18,20]$. Recently, Zanos et al. [19] discovered that the fast antidepressant-like effects of ketamine seem to be dependent on ketamine's metabolism. In mice, the ketamine metabolite (2R, 6R)-hydroxynorketamine exhibits an antidepressant-like effect similar to ketamine that is independent of NMDAR binding, but dependent on AMPAR activity. Pretreatment of the animals with NBQX prevented the antidepressant-like effect of (2R, 6R)-hydroxynorketamine [19].

A dose-response study in rats using microdialysis revealed that low doses of ketamine $\left(10,20\right.$, and $\left.30 \mathrm{mg} \mathrm{kg}^{-1}\right)$ augment glutamate outflow in the prefrontal cortex and increase glutamatergic neurotransmission. In contrast, an intermediate dose of ketamine $\left(50 \mathrm{mg} \mathrm{kg}^{-1}\right)$ has no effect and an anesthetic dose of ketamine (200 mg kg-1) decreases extracellular glutamate levels, which is blocked when the AMPA/kainite receptor antagonist 6-cyano7-nitroquinoxaline-2,3-dione was applied to the intraprefrontal cortex [21].

A more detailed study on the glutamatergic and GABAergic system including receptors, modulators, and affected pathways is critical for the identification of new therapeutic targets for MDD drug development efforts with the goal of avoiding undesired side effects.

In the present study, we performed metabolomics and proteomics analyses in mice that revealed hippocampal alterations of GABA, glutamate, and glutamine metabolite levels and ratios as well as GABAR and AMPAR protein levels in response to a low dose of ketamine.

We chose the hippocampus as a relevant brain region for studying MDD and ketamine's antidepressant-like effects [22-26]. Magnetic resonance imaging analyses revealed hippocampal volume reduction during acute depressive episodes that are believed to be involved in the pathobiology of MDD [27-29]. The volume changes are already apparent during the first depressive episode and are present during an acute episode of MDD [30]. Hippocampal volume reduction might result from neuronal cell loss, pruning of apical dendrites in the hippocampal CA3 subregion, decreased dentate gyrus neurogenesis, and a loss of glial cells [31-33]. These effects can be reversed by antidepressant treatment, and hippocampal volume reduction seems to be less prominent or even absent in phases of remission [28]. Patients with MDD exhibit memory impairments - which is dependent on the hippocampus - as well as a dysregulated connectivity network of several brain regions including the hippocampus $[34,35]$.

\section{Material and Methods}

Animals and Ketamine Treatment

Eight-week-old male C57BL/6 mice (Charles River Laboratories, Maastricht, The Netherlands) were first singly housed for 2 weeks under standard conditions (12 h) light/dark cycle, lights on 
at 06.00 a.m., room temperature $23 \pm 2{ }^{\circ} \mathrm{C}$, humidity $60 \%$, tap water and food ad libitum) in the facilities of the Max Planck Institute of Psychiatry. After habituation, the mice were treated intraperitoneally with S-ketamine ( $3 \mathrm{mg} \mathrm{kg}^{-1}$, Pfizer, Karlsruhe, Germany) or vehicle ( $0.9 \%$ saline solution) and a forced swim test (FST) was performed 2, 14, 24, and $72 \mathrm{~h}$ after ketamine treatment and animals were killed by an overdose of isoflurane (Forene, Abbott, Wiesbaden, Germany). The animals were subsequently perfused with $0.9 \%$ ice-cold saline solution, decapitated, and brains were dissected, shock-frozen in liquid nitrogen, and stored at $-80^{\circ} \mathrm{C}$ until further analyses. The experiments were performed in accordance with the European Communities Council Directive 86/609/EEC. The protocols were approved by the committee for the Care and Use of Laboratory Animals of the Government of Upper Bavaria, Germany.

\section{Forced Swim Test}

Each mouse was put into a 2-L glass beaker (diameter: $13 \mathrm{~cm}$, height: $24 \mathrm{~cm})$ filled with tap water $\left(21 \pm 1^{\circ} \mathrm{C}\right)$ to a height of $15 \mathrm{~cm}$, so that the mouse could not touch the bottom with its hind paws or tail. Testing duration was $6 \mathrm{~min}$ and at the end of the test the animals were immediately dried with a towel and returned to their home cage. The floating time was scored $2 \mathrm{~h}$ (ketamine-treated animals: $n=33$, vehicle-treated animals: $n=33$ ), $14 \mathrm{~h}$ (ketaminetreated animals: $n=31$, vehicle-treated animals: $n=29), 24 \mathrm{~h}$ (ketamine-treated animals: $n=33$, vehicle-treated animals: $n=33$ ), and $72 \mathrm{~h}$ (ketamine-treated animals: $n=31$, vehicle-treated animals: $n=29$ ) after ketamine treatment by an experienced observer, blind to the condition of the animals.

\section{Isolation of Membrane-Associated (MF) Proteins}

MF proteins were prepared by repeated tissue homogenization and extraction of non-membrane-associated proteins and solubilization of MF proteins with sodium dodecyl sulfate (SDS). For this purpose, tissues were homogenized for $30 \mathrm{~s}$ in $1 \mathrm{~mL}$ of $2 \mathrm{M} \mathrm{NaCl}$, $10 \mathrm{~mm}$ Hepes/NaOH, pH 7.4, containing $1 \mathrm{~mm}$ EDTA, phosphatase inhibitor cocktail 2 and 3 (Sigma-Aldrich, Munich, Germany), protease inhibitor cocktail Tablets "cOmplete" (Roche Diagnostics, Mannheim, Germany), then incubated for $10 \mathrm{~min}$ and homogenized again for $30 \mathrm{~s}$ and further with a ultrasonicator for $3 \times$ $10 \mathrm{~s}$ on ice. The homogenates were centrifuged at $16,100 \mathrm{~g}$ at $4{ }^{\circ} \mathrm{C}$ for $20 \mathrm{~min}$. The supernatant contained the cytoplasmic (CF) proteins. The pellets were rehomogenized in $1 \mathrm{~mL}$ of $0.1 \mathrm{M} \mathrm{Na}_{2} \mathrm{CO}_{3}$ and $1 \mathrm{mM}$ EDTA containing $1 \mathrm{mM}$ EDTA, phosphatase inhibitor cocktail 2 and 3 (Sigma-Aldrich, Munich, Germany), protease inhibitor cocktail Tablets "cOmplete" (Roche Diagnostics, Mannheim, Germany), $\mathrm{pH} 11.3$, mixed at $4^{\circ} \mathrm{C}$ for 30 min and collected by centrifugation $\left(16,100 \mathrm{~g}\right.$ at $4^{\circ} \mathrm{C}$ for $\left.20 \mathrm{~min}\right)$. Subsequently, the pellets were extracted with $5 \mathrm{M}$ urea, $100 \mathrm{mM} \mathrm{NaCl}, 10 \mathrm{mM}$ HEPES, pH 7.4, and $1 \mathrm{~mm}$ EDTA containing $1 \mathrm{mM}$ EDTA, phosphatase inhibitor cocktail 2 and 3 (Sigma-Aldrich, Munich, Germany), protease inhibitor cocktail Tablets "cOmplete" (Roche Diagnostics, Mannheim, Germany) and then washed twice with 0.1 $\mathrm{M}$ Tris/ $\mathrm{HCl}$, containing $1 \mathrm{mM}$ EDTA, phosphatase inhibitor cocktail 2 and 3 (Sigma-Aldrich, Munich, Germany), protease inhibitor cocktail Tablets "cOmplete" (Roche Diagnostics, Mannheim, Germany) $\mathrm{pH} 7.6$. The pellets were solubilized in $20-50 \mu \mathrm{L}$ of $2 \%$ SDS, $50 \mathrm{mM}$ dithiothreitol, and $0.1 \mathrm{M}$ Tris/ $\mathrm{HCl}$, containing $1 \mathrm{mM} \mathrm{EDTA}$, phosphatase inhibitor cocktail 2 and 3 (Sigma-Aldrich, Munich, Germany), protease inhibitor cocktail Tablets "cOmplete" (Roche
Diagnostics, Mannheim, Germany) $\mathrm{pH} 7.6$, at $90^{\circ} \mathrm{C}$ for $1 \mathrm{~min}$ and stored at $-20^{\circ} \mathrm{C}$ until further analysis.

\section{Western Blot}

Hippocampal MF proteins from 8-week-old male C57BL/6 mice treated with ketamine for $2,14,24$, and $72 \mathrm{~h}$ were fractionated by SDS-polyacrylamide gel electrophoresis, and Western Blot was performed based on standard protocols. After electrophoresis, proteins were transferred to PVDF membranes (Immobilon-P, Millipore, Billerica, MA, USA). Primary antibodies were against myelin basic protein (MBP, Abcam, Cambridge, UK). Anti-rabbit, anti-mouse ECL horseradish peroxidase-linked secondary antibodies (GE Healthcare Life Sciences, Little Chalfont, Buckinghamshire, UK) were used. The densitometric analyses were performed with the Image Lab software (Bio-Rad, Munich, Germany).

\section{Sample Preparation for Liquid Chromatography-ESI-Mass}

Spectrometry Analyses

Protein Sample Preparation for Quantitative Proteomics

Analyses

Hippocampal CF and MF proteins were mixed 1:1 with CF and MF ${ }^{15} \mathrm{~N}$-labeled internal standards respectively. In vivo ${ }^{15} \mathrm{~N}$-labeled hippocampal proteins were derived from C57BL/6 mice that were fed with a ${ }^{15} \mathrm{~N}$ diet (Silantes, Munich, Germany) for 12 weeks. $50 \mu \mathrm{g}$ of the ${ }^{14} \mathrm{~N} /{ }^{15} \mathrm{~N}$ protein mixture were separated by SDS-polyacrylamide gel electrophoresis. Separated proteins were stained with Coomassie Brilliant Blue for $20 \mathrm{~min}$ and destained overnight. Each gel lane was cut into $162.5 \mathrm{~mm}$ slices per biological replicate and each slice further cut into smaller pieces.

In-Gel-Trypsin Digestion and Peptide Extraction

The gel pieces were covered with $100 \mu \mathrm{L}$ of $25 \mathrm{mM} \mathrm{Na}_{4} \mathrm{H}$ $\mathrm{CO}_{3} / 50 \% \mathrm{ACN}$ for complete destaining and mixed for $10 \mathrm{~min}$ at room temperature. The supernatant was discarded and this step repeated twice. Proteins were reduced with $75 \mathrm{~L} 1 \times$ DTT/25 mM $\mathrm{NH}_{4} \mathrm{HCO}_{3}$ and incubated at $56 \mathrm{C}$ for $30 \mathrm{~min}$ in the dark. The supernatant was discarded and for alkylation, $100 \mu \mathrm{L}$ IAM was added to the gel pieces and mixed for $30 \mathrm{~min}$ at room temperature. The supernatant was discarded and the gel pieces washed twice with $100 \mu \mathrm{L} 25 \mathrm{mM} \mathrm{Na}_{4} \mathrm{HCO}_{3} / 50 \% \mathrm{ACN}$ and incubated for $10 \mathrm{~min}$ at room temperature. The supernatant was discarded and gel pieces dried for approximately $20 \mathrm{~min}$ at room temperature. Proteins were digested with $50 \mu \mathrm{L}$ trypsin solution $(5 \mathrm{ng} / \mu \mathrm{L}$ trypsin $/ 25 \mathrm{mM}$ $\mathrm{NH}_{4} \mathrm{HCO}_{3}$ ) overnight at $37^{\circ} \mathrm{C}$. Peptides were extracted from the gel pieces by incubating them in $50 \mu \mathrm{L}$ of $2 \% \mathrm{FA} / 50 \% \mathrm{ACN}$ for 20 min at $37^{\circ} \mathrm{C}$ followed by $5 \mathrm{~min}$ sonication. This step was repeated twice with $50 \mu \mathrm{L}$ of $1 \% \mathrm{FA} / 50 \% \mathrm{ACN}$. The supernatants were then combined and dried (Speed Vac Plus, SC 210 A, Savant). The pellet was stored at $-20^{\circ} \mathrm{C}$.

Quantitative Proteomics Analyses by Liquid Chromatography Tandem Mass Spectrometry

Hippocampal MF and CF proteins were identified and quantified with a Dionex Ultimate 3000 RSLC nanoUPLC (Thermo Fisher Scientific, Waltham, MA, USA) system and a Q Exactive ${ }^{\mathrm{TM}}$ Orbitrap ${ }^{\mathrm{TM}}$ mass spectrometer. Separation of peptides was performed by reversed-phase chromatography at a flow rate of $300 \mathrm{~nL} / \mathrm{min}$ (Thermo Scientific PepMap C18, $2 \mu \mathrm{m}$ particle size, 100A pore size, $75 \mu \mathrm{m} \times 50 \mathrm{~cm}$ length). Peptides were loaded onto a pre-column (Thermo Scientific PepMap 100 C18, $5 \mu \mathrm{m}$ particle size, 100A pore size, $300 \mu \mathrm{m} \times 5 \mathrm{~mm}$ length) in $0.1 \%$ FA for $3 \mathrm{~min}$ at a flow
Weckmann et al. 
Table 1. Hippocampal glutamatergic and GABAergic system-related (a) metabolite and (b) protein alterations after a single injection of a low dose of ketamine $\left(3 \mathrm{mg} \mathrm{kg}^{-1}\right) ; n=5$ per group and time point

a

\begin{tabular}{llccccc}
\hline Metabolite & HMBD & FC & $\begin{array}{l}\text { Time } \\
\text { point, h }\end{array}$ & $\begin{array}{l}\text { PLS-DA, } \\
\text { VIP-score }\end{array}$ & $\begin{array}{l}\text { SAM, } \\
p \text { value }\end{array}$ & $\begin{array}{l}\text { SAM, } \\
q \text { value }\end{array}$ \\
\hline GABA & HMDB00112 & 1.13 & 72 & 1.57 & 0.044 & 0.22 \\
Glutamate & HMDB00148 & 0.90 & 14 & 1.40 & 0.041 & 0.14 \\
Glutamine & HMDB00641 & 0.77 & 14 & 1.87 & 0.002 & 0.07 \\
Putrescine & HMDB01414 & 3.32 & 2 & 1.49 & 0.020 & 0.07 \\
Serine & HMDB00187 & 1.14 & 2 & 1.32 & 0.049 & 0.08 \\
\hline
\end{tabular}

b

\begin{tabular}{llccccc}
\hline Protein ID & Protein name & FC & $\begin{array}{l}\text { Time } \\
\text { point, h }\end{array}$ & $\begin{array}{l}\text { PLS-DA, } \\
\text { VIP-score }\end{array}$ & $\begin{array}{l}\text { SAM, value } \\
p \text { val }\end{array}$ & $\begin{array}{l}\text { SAM, } \\
q \text { value }\end{array}$ \\
\hline GABA $_{\mathrm{A}} \mathrm{R}$ & GABA receptor subunit $\alpha 1$ & 0.33 & 2 & 1.66 & 0.00882 & 0.095 \\
Gria2 & AMPA receptor subunit 2 & 1.61 & 2 & 1.66 & 0.00789 & 0.073 \\
Gria3 & AMPA receptor subunit 3 & 0.65 & 2 & 1.67 & 0.00756 & 0.071 \\
\hline
\end{tabular}

PLS-DA, partial least square-discriminant analysis; FC, fold change; SAM, significance analysis of microarrays (and proteins, metabolites); VIP, variable importance in projection; FDR, false discovery rate; ID, identification; HMDB, human metabolome database; AMPA, alpha-amino-3-hydroxy-5-methyl-4-isoxazolepropionic acid; GABA; gamma-aminobutyric acid.

rate of $10 \mu \mathrm{L} / \mathrm{min}$. Chromatography was performed using the following solvents: solvent A water + $0.1 \% \mathrm{FA}$, solvent B $80 \% \mathrm{ACN}$, $20 \%$ water $+0.1 \%$ FA. A linear gradient of $2-40 \%$ B for 30 min was used. The liquid chromatography (LC) eluant was sprayed into the mass spectrometer by means of an easy-spray source (Thermo Fisher Scientific). All $\mathrm{m} / \mathrm{z}$ values of eluting ions were measured in an Orbitrap mass analyzer, set at a resolution of 70,000. Data-dependent scans (Top 20) were employed to automatically isolate and generate fragment ions by high-energy collisional dissociation in the quadrupole mass analyzer and measurement of the resulting fragment ions was performed in the Orbitrap analyser, set at a resolution of 17,500. Peptide ions with charge states of $2+$ to $4+$ and above were selected for fragmentation.

Orbitrap $^{\mathrm{TM}}$ raw files were converted to mzXML files using MSConvert software. The in-house software package iSPY, which was adapted from an earlier version of a peptide quantitation program known as iTracker, was used to identify and quantify peptides [36]. The software was used to convert mzXML to mgf files that were then finally imported into Mascot and searched against the SwissProt Mouse database and a decoy database. The databases were searched using the following settings: variable modifications of carbamidomethyl (cys), oxidation (met); 20 ppm peptide tolerance, $0.1 \mathrm{Da} \mathrm{MS} / \mathrm{MS}$ tolerance, 2 missed cleavages and peptide charge state of $+2,+3$, or +4 . In iSPY, Mascot dat output files were run through Percolator for improved identification. Non-unique peptides were discarded. Only peptides with a protein type 1 error of less than 0.01 were kept in the final dataset. The heavy and light peak intensities for each peptide were calculated in iSPY using retention time and sequence information from the MS1 spectra and Mascot search respectively. The intensities for a pre-specified

Ketamine's Effects on the Glutamatergic

and GABAergic Systems number of isotopomeric peaks were calculated by scanning through a retention window spanning a set distance either side of the maximum intensity value. The ${ }^{14} \mathrm{~N}$ and ${ }^{15} \mathrm{~N}$ peptide isotopic peaks from the MS1 dataset were used to compare the theoretical mass difference between the heavy and light peptides, and the typical isotopic distribution patterns. Only quantifiable peptides (those for which both a heavy and a light peak intensity were identified in 5 replicates) were included in the dataset.

\section{Isolation of Polar Metabolites from Mouse Tissue}

Mouse tissues were homogenized $\left(2 \mathrm{~min} \times 1,200 \mathrm{~min}^{-1}\right.$, homogenizer PotterS, Sartorius, Göttingen, Germany) in 30-fold icecold $80 \%$ methanol. Samples were centrifuged $(14,000 \mathrm{~g}, 10 \mathrm{~min}$, $4{ }^{\circ} \mathrm{C}$ ) and the supernatants were incubated on dry ice. Afterwards, the pellets were incubated in six-fold ice-cold $80 \%$ methanol and then combined with the previous supernatants. The metabolite extracts were vortexed, centrifuged $\left(14,000 \mathrm{~g}, 10 \mathrm{~min}, 4^{\circ} \mathrm{C}\right)$, and the solution was dried (Speed Vac Plus, SC 210 A, Savant). Samples were stored at $-80^{\circ} \mathrm{C}$.

\section{Targeted Metabolomics Analysis}

Samples were resuspended using $20 \mu \mathrm{L}$ LC-mass spectrometry (MS/MS) grade water, of which $10 \mu \mathrm{L}$ were injected and analyzed using a 5500 QTRAP triple quadrupole mass spectrometer (AB/ SCIEX, Framingham, MA, USA) coupled to a Prominence UFLC high-performance LC system (Shimadzu, Columbia, SC, USA) via selected reaction monitoring (SRM) of a total of 293 endogenous water-soluble metabolites for steady-state analyses of samples.

Samples were delivered to the mass spectrometer via normal phase chromatography using a $4.6 \mathrm{~mm} \times 10 \mathrm{~cm}$ Amide Xbridge 


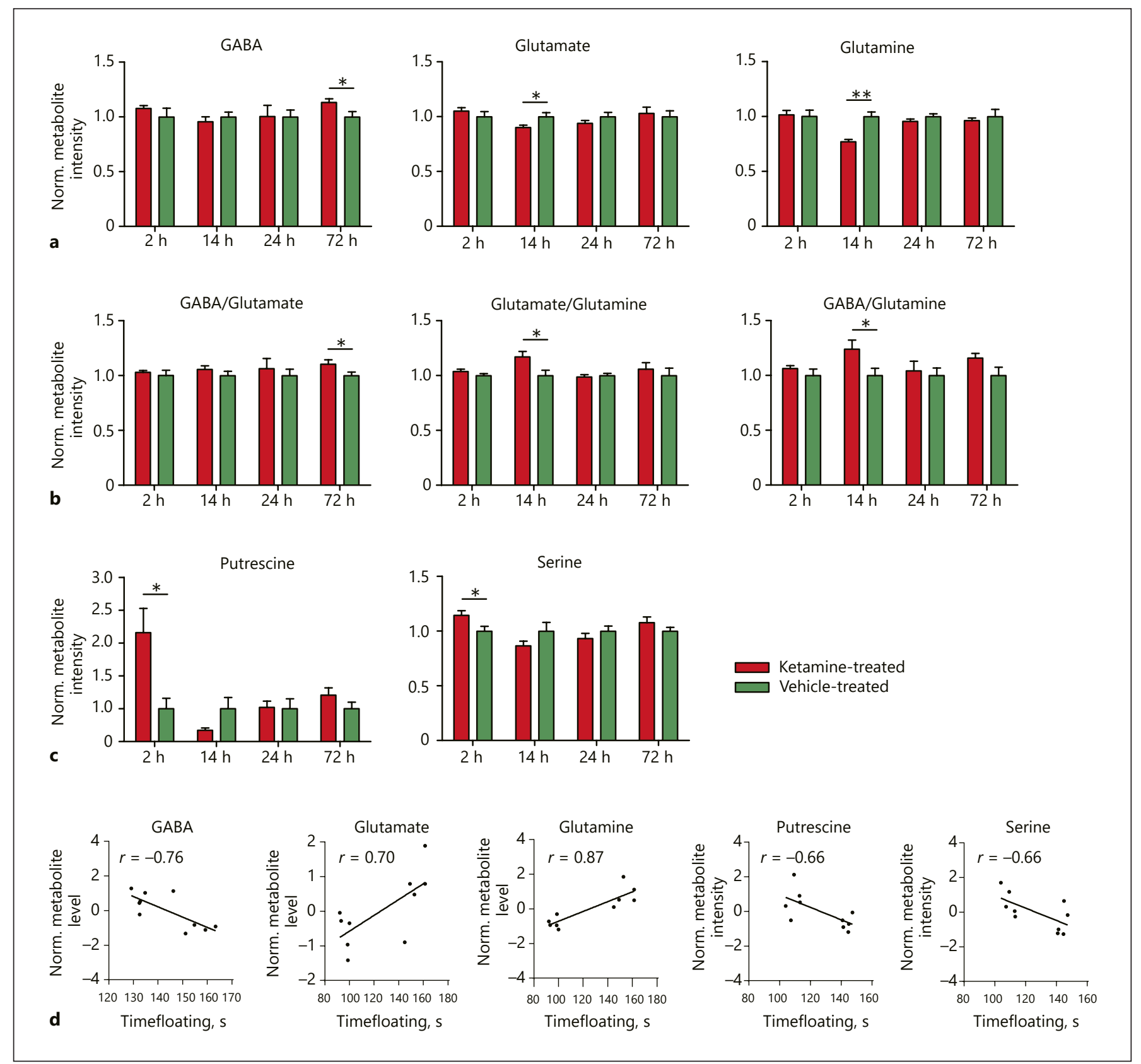

Fig. 1. Hippocampal metabolite level, ratio, and correlation analyses upon a single injection of a low dose of ketamine $\left(3 \mathrm{mg} \mathrm{kg}^{-1}\right)$. a Time-dependent metabolite levels of GABA, glutamate, and glutamine. b Glutamate/GABA, glutamate/glutamine and GABA/ glutamine metabolite ratios determined by time-dependent metabolomics analyses. c Time-dependent metabolite level changes of NMDAR positive modulators putrescine and serine. $\mathbf{d}$ Correla-

HILIC column (Waters, Milford, CT, USA) at $350 \mu \mathrm{L} \mathrm{min}{ }^{-1}$. Gradients were run starting from $85 \%$ buffer $B$ (high-performance LC grade $\mathrm{ACN}$ ) to $42 \% \mathrm{~B}$ from 0 to $5 \mathrm{~min} ; 42 \% \mathrm{~B}$ to $0 \% \mathrm{~B}$ from 5 to 16 min; $0 \%$ B was held from 16 to $24 \mathrm{~min} ; 0 \%$ B to $85 \%$ B from 24 to tion analyses of GABA, glutamate, glutamine, putrescine, and serine metabolite intensities with the FST floating time. ${ }^{*} p \leq 0.05$, ** $p \leq 0.01$. $p$ values were determined by SAM. Error bars represent SEM. The correlation coefficient, $r$, was calculated by Pearson. The linear regression line is shown only for significant $(p \leq 0.05)$ correlation coefficients.

$25 \mathrm{~min}$; 85\% B was held for $7 \mathrm{~min}$ to re-equilibrate the column. Buffer A comprised $20 \mathrm{mM}$ ammonium hydroxide/ $20 \mathrm{mM}$ ammonium acetate ( $\mathrm{pH} 9.0$ ) in 95:5 water:ACN. Some metabolites were targeted in both positive and negative ion modes for SRM transi- 
Fig. 2. Hippocampal protein level and correlation analyses after a single injection of a low dose of ketamine $\left(3 \mathrm{mg} \mathrm{kg}^{-1}\right)$. a Alterations of $\mathrm{GABA}_{\mathrm{A}}$ receptor $a 1$ $\left(\mathrm{GABA}_{\mathrm{A}} \mathrm{Ra1}\right)$, and AMPA receptor subunits Gria2 and Gria3 protein levels determined by quantitative mass spectrometry analyses $2 \mathrm{~h}$ after ketamine treatment. b Correlation analyses of $\mathrm{GABA}_{\mathrm{A}} \mathrm{Ra} 1$, Gria2 and Gria3 protein intensities with the FST floating time $(p \leq 0.05) .{ }^{* *} p \leq 0.01$. $p$ values were determined by SAM. Error bars represent s.e.m. The correlation coefficient, $r$, was calculated by Pearson. The linear regression line is shown only for significant $(p \leq 0.05)$ correlation coefficients.
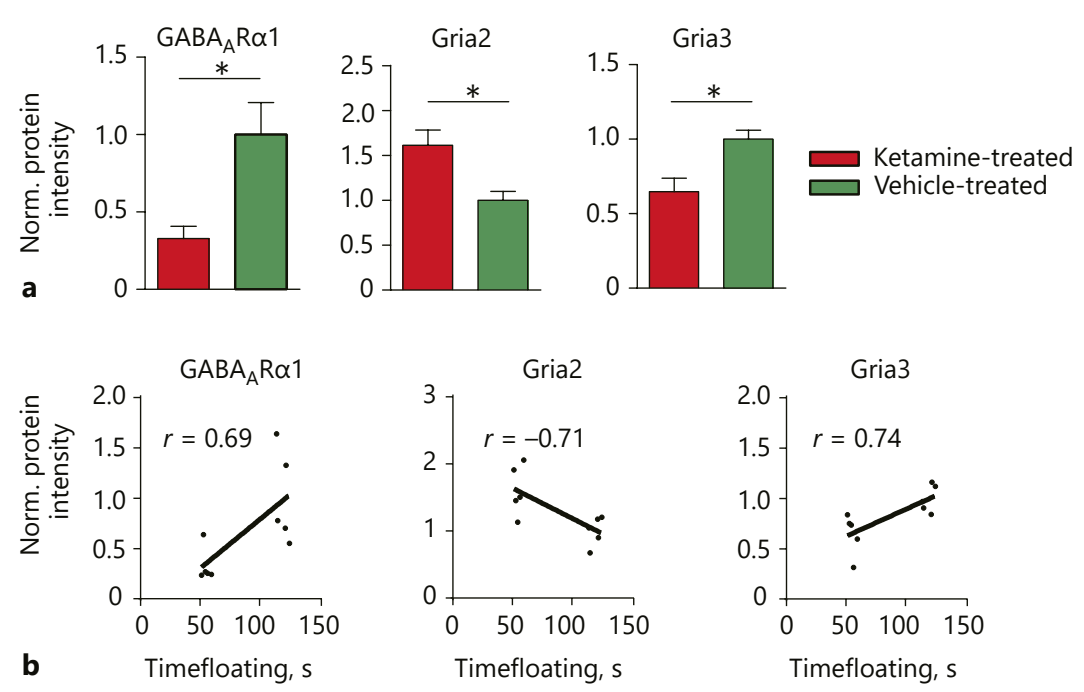

tions using positive/negative polarity switching. Electrospray ionization voltage was $+4,900 \mathrm{~V}$ in the positive ion mode and $-4,500$ $\mathrm{V}$ in the negative ion mode. The dwell time was $4 \mathrm{~ms}$ per SRM transition and the total cycle time was $1.89 \mathrm{~s}$. Approximately 9-12 data points were acquired per detected metabolite. Peak areas from the total ion current for each metabolite-SRM transition were integrated using the MultiQuant version 2.0 software (AB/SCIEX) [37]. Animals from the same cohort were used for all metabolomics analyses.

\section{Statistics and Data Analyses}

Identification of Significant Metabolite and Protein Level

Alterations

Metabolite intensities as well as protein ratios were mediannormalized and autoscaled for statistical analysis. Significant metabolite and protein level changes upon ketamine treatment were identified by multivariate partial least squares-discriminant analyses and high-dimensional feature selection significance analysis of microarrays and other - omics datasets (SAM) using MetaboAnalyst [38]. The quality of the partial least squares-discriminant analyses models was assessed for $\mathrm{R}^{2}, \mathrm{Q}^{2}$ and accuracy values with variable influence of projection-score and for SAM with $q$ value and false discovery rate [39]. We improved the robustness of our data analyses and increased confidence in significantly altered metabolites and proteins by considering the 2 different statistical methods.

\section{Calculation of Metabolite Pair Ratios}

The median-normalized metabolite intensities before autoscaling of selected pairs of metabolites were used to calculate metabolite ratios. For statistical analyses, Student's $t$ test was performed by using the metabolite ratio of interest for each ketamineand vehicle-treated animal (e.g., metabolite $\mathrm{x} /$ metabolite $\mathrm{y}$ of one ketamine-treated animal) calculated by dividing the metabolite intensity of metabolite $\mathrm{x}$ by the intensity of metabolite $\mathrm{y}$ for each time point. The final metabolite ratio of interest (e.g., metabolite $\mathrm{x} /$ metabolite $\mathrm{y}$ for all ketamine- and vehicle-treated animals) was then calculated by dividing the average metabolite intensities of all ketamine-treated animals by the average metabolite intensities of all vehicle-treated animals [40].

\section{Results}

In the present study, C57BL/6 wild-type mice were treated with a single injection of a low dose of ketamine $\left(3 \mathrm{mg} \mathrm{kg}^{-1}\right)$ for $24 \mathrm{~h}$ and the antidepressant-like behavior was assessed using the FST. To address the molecular effects of ketamine $\left(3 \mathrm{mg} \mathrm{kg}^{-1}\right)$ on the glutamatergic and GABAergic system, we analyzed the hippocampal metabolome and proteome of ketamine- and vehicle-treated mice by an SRM-based, targeted metabolomics platform and a proteomics workflow based on in vivo ${ }^{15} \mathrm{~N}$ metabolic labeling and quantitative MS/MS.

We analyzed glutamatergic and GABAergic metabolites and proteins of ketamine- and vehicle-treated mice. GABA, glutamate, glutamine, putrescine, serine, $\mathrm{GABA}_{\mathrm{A}}$ Ra1, AMPAR subunit 2 (Gria2), and AMPAR subunit 3 (Gria3) levels were significantly altered (Table 1).

We further examined the levels of the 3 amino acids and the GABA/glutamate, glutamate/glutamine, and GABA/glutamine ratios. GABA levels were upregulated at $72 \mathrm{~h}$, whereas glutamate and glutamine levels were significantly decreased $14 \mathrm{~h}$ after a single injection of a low dose of ketamine (Fig. 1a and Table 1). In addition, the GABA/glutamate ratio at $72 \mathrm{~h}$ and the glutamate/glutamine and $\mathrm{GABA} /$ glutamine ratios at $14 \mathrm{~h}$ were increased 


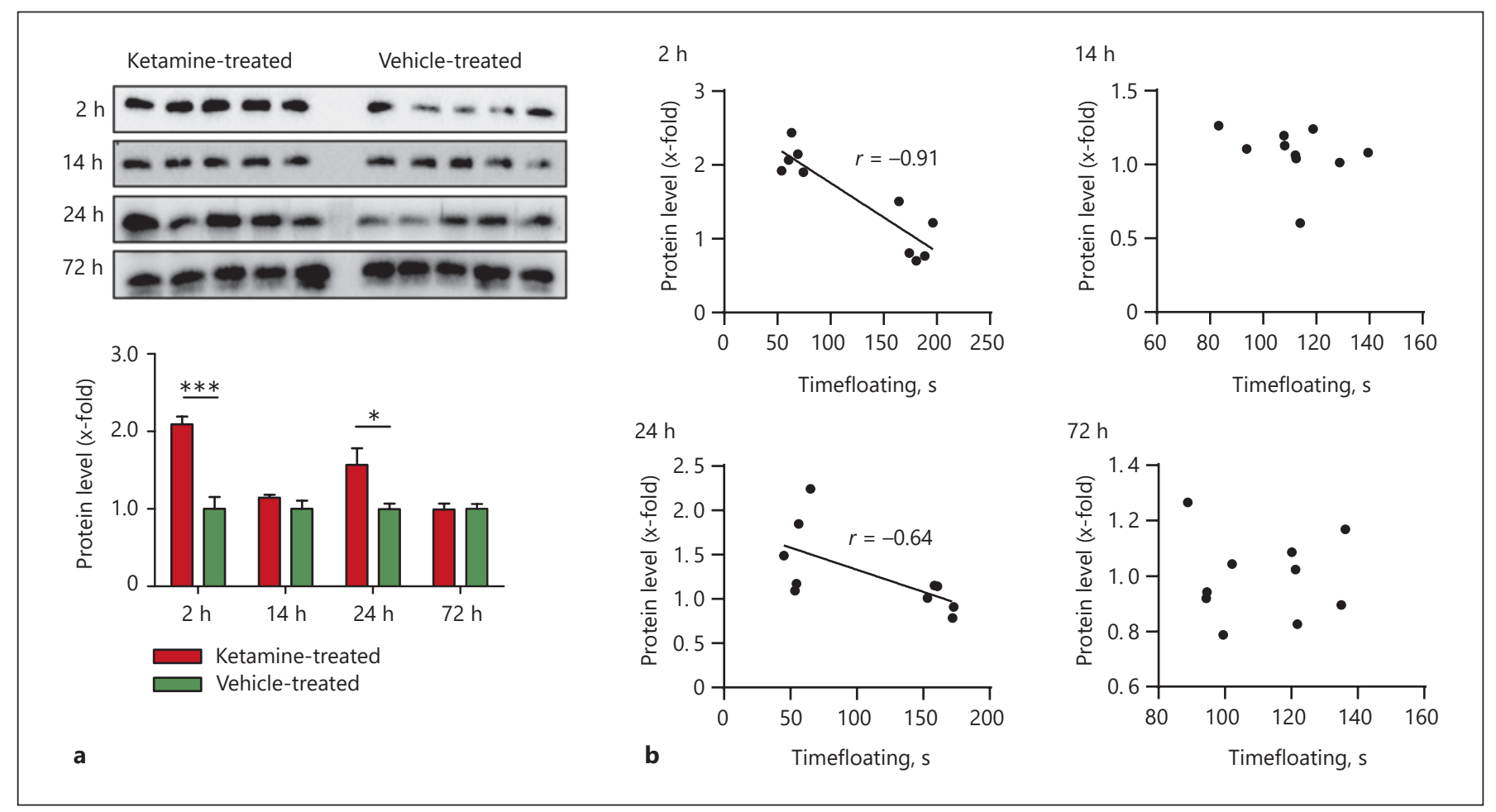

Fig. 3. Hippocampal MBP level and correlation analyses upon a single injection of a low dose of ketamine $\left(3 \mathrm{mg} \mathrm{kg}^{-1}\right)$. a Timedependent Western blot analyses of MBP 2, 14, 24, and $72 \mathrm{~h}$ after a single injection of ketamine. $n=5$ mice per group and time point. ${ }^{*} p \leq 0.05,{ }^{* * *} p \leq 0.001$. $p$ values were determined by Student's $t$ test. Error bars represent SEM. The results from ketamine-treated animals are normalized to the ones obtained from vehicle treatment (mean value $=1$ ). $\mathbf{b}$ Correlation analyses of MBP protein levels with the FST floating time $(p \leq 0.05)$. The correlation coefficient, $r$, was calculated by Pearson. The linear regression line is shown only for significant $(p \leq 0.05)$ correlation coefficients. after a single injection of ketamine (Fig. 1b). Interestingly, metabolite levels of 2 positive modulators of the NMDAR - putrescine and serine - were elevated already $2 \mathrm{~h}$ after a single injection of ketamine (Fig. $1 \mathrm{c}$ and Table 1). Furthermore, GABA, glutamate, glutamine, putrescine, and serine metabolite levels correlated statistically and significantly with the behavioral FST floating time (Fig. 1d).

Next, we analyzed proteins relevant for the glutamatergic and GABAergic systems, whereas $\mathrm{GABA}_{\mathrm{A}} \mathrm{Ra} 1$ and AMPAR subunit Gria3 protein levels were downregulated. We observed increased AMPAR subunit Gria2 protein levels $2 \mathrm{~h}$ after ketamine administration (Fig. 2a and Table 1). Moreover, levels for all 3 proteins significantly correlated with the FST floating time (Fig. 2b).

Ours as well as previous results on ketamine's effects on the glutamatergic and GABAergic system as well as on neuronal plasticity, respectively, led us to analyze ketamine's potential on myelination. The myelin sheath is a protective lipid layer around axons produced by glial cells [41]. Our proteomics data indicated increased (however, not significant) MBP levels $2 \mathrm{~h}$ after ketamine treatment (see online supplementary Figure 1, available at www.karger.com/doi/10.1159/000493425). We decided to further analyze MBP levels by Western blot - additionally for the 14 and $72 \mathrm{~h}$ time points. Interestingly, ketamine treatment results in an increase of MBP levels already 2 and $24 \mathrm{~h}$ after a single injection (Fig. 3a). Moreover, MBP levels also correlated statistically and significantly with the behavioral FST floating time at the 2 and $24 \mathrm{~h}$ time point (Fig. 3b).

\section{Discussion/Conclusion}

In the mammalian central nervous system, AMPARs mediate the majority of fast excitatory synaptic transmission. Gria2 is a critical subunit that determines mammalian AMPAR function. It dictates the critical biophysical properties of the receptor, influences receptor assembly
48

Mol Neuropsychiatry 2019;5:42-51 DOI: $10.1159 / 000493425$
Weckmann et al. 
and trafficking, and plays a pivotal role in long-term synaptic plasticity [42].

Homeostatic synaptic plasticity is distinct from inputspecific Hebbian forms of synaptic plasticity such as LTP, and is induced by chronically blocking neuronal activity or glutamatergic transmission in cultured neurons [4345]. Previous studies had shown that ketamine increases AMPAR subunits Gria1 and Gria2 as well as other synaptic protein levels. Furthermore, ketamine induces LTP and increases the number of spines in the prefrontal cortex of rats $[18,19]$. In the present study, ketamine was found to decrease $\mathrm{GABA}_{\mathrm{A}} \mathrm{R} \alpha 1$ and AMPAR subunit Gria3 levels and elevate AMPAR subunit Gria2 levels, changing AMPAR composition in favor of Gria2. Furthermore, all 3 protein levels significantly correlated with the FST floating time.

Glutamate and GABA metabolite levels decreased $14 \mathrm{~h}$ and increased again $72 \mathrm{~h}$ after ketamine injection. GABA and glutamate levels correlated with the FST floating time indicative of the antidepressant-like effects. Glutamine is metabolized to glutamate and GABA and then recycled in the respective glutamate/glutamine and GABA/glutamine pathways [46-48]. Glutamine metabolite levels decreased and glutamate/glutamine and GABA/ glutamine ratios increased $14 \mathrm{~h}$ after ketamine treatment. These results appear to be contradictory to previous data where increased glutamate outflow in the prefrontal cortex was found after ketamine treatment. A possible explanation is that prefrontal cortex glutamate levels in the earlier study were measured extracellularly, whereas our data reflect total cellular metabolite levels. Glutamate and GABA release is dependent on inhibitory and excitatory neuron activities. The observed neurotransmitter level changes represent the total pool and not the released levels of glutamate, GABA, and glutamine.

Interestingly, levels for 2 positive modulators of the NMDAR - serine and putrescine - are elevated and significantly correlate with the FST floating time $2 \mathrm{~h}$ after a single injection of ketamine. We speculate that the fast antidepressant-like effects of ketamine could be even more pronounced by an augmentation therapy with these NMDAR modulators. In this regard, putrescine has already been shown to exhibit a fast antidepressant effect in the FST [49].

A loss of hippocampal volume has been observed for a subset of MDD patients. This process can be reversed by $\mathrm{AD}$ treatment, which also results in symptom reduction. The volume decline by neuronal atrophy is due to weakened and shrunk synaptic connections and seems to be caused by stress. The observed reversal of the volume reduction in MDD patients might be the result of increased synaptic plasticity [50-54]. A low dose of ketamine has previously been shown to induce synaptic plasticity that was apparent by newly formed spines in the prefrontal cortex of rats [18]. However, when applied at higher doses, ketamine $\left(6 \mathrm{mg} \mathrm{kg}^{-1}\right)$ results in a loss of the myelin sheath $[12,13,55]$. At higher, but still subanesthetic doses, ketamine $\left(6 \mathrm{mg} \mathrm{kg}^{-1}\right)$ results in a schizophrenia-like phenotype in rodents with loss of the myelin sheath. We found that ketamine treatment at low doses $\left(3 \mathrm{mg} \mathrm{kg}^{-1}\right)$ results in increased MBP protein levels at the 2 and $24 \mathrm{~h}$ time points. This rules out that the drug dose we used in this study produces molecular alterations that were observed in the ketamine-induced mouse models of schizophrenia, which show decreased myelin protein levels.

Taken together and in line with previous research, our data indicate that ketamine impacts the AMPAR subunit Gria2 and results in decreased GABAergic inhibitory neurotransmission leading to increased excitatory neuronal activity. The increased levels of the positive NMDAR modulators putrescine and serine following ketamine treatment are in line with this finding. Our finding of elevated MBP protein levels is consistent with the enhanced axonal outgrowth and/or strengthening of the axonal signal transmission after ketamine treatment found in earlier studies. We submit that the observed increased AMPAR subunit Gria2 and reduced $G_{A B A} R$ protein levels in combination with higher MBP protein levels are critical for the fast antidepressant-like effect of ketamine.

\section{Acknowledgments}

KW was supported by the International Max Planck Research School for Molecular and Cellular Life Sciences. The technical support by Maria Holzapfel is gratefully acknowledged.

\section{Statement of Ethics}

Animal experiments conform to internationally accepted standards and have been approved by the appropriate institutional review body.

\section{Disclosure Statement}

The authors have no financial interests or potential conflicts of interest to disclose. 


\section{Funding Source}

This work was supported by the Max Planck Society and the European commission via the FP7 Prime XS project.

\section{Author Contributions}

K.W., M.M., and C.W.T.: designed the research; K.W., M.J.D., J.A.H., and R.F.: performed the research; F.D., C.W., M.D.F., C.L., G.M., J.M.A., and K.S.L.: contributed analytic tools; K.W., M.J.D., and C.L.: analyzed data; K.W. and C.W.T.: wrote the paper.

\section{References}

1 Berman RM, Cappiello A, Anand A, Oren DA, Heninger GR, Charney DS, et al. Antidepressant effects of ketamine in depressed patients. Biol Psychiatry. 2000 Feb;47(4):351-4.

2 Hirota K, Lambert DG. Ketamine: its mechanism(s) of action and unusual clinical uses. Br J Anaesth. 1996 Oct;77(4):441-4.

3 Krystal JH, D’Souza DC, Petrakis IL, Belger A, Berman RM, Charney DS, et al. NMDA agonists and antagonists as probes of glutamatergic dysfunction and pharmacotherapies in neuropsychiatric disorders. Harv Rev Psychiatry. 1999 Sep-Oct;7(3):125-43.

4 Krystal JH, Sanacora G, Blumberg H, Anand A, Charney DS, Marek G, et al. Glutamate and GABA systems as targets for novel antidepressant and mood-stabilizing treatments. Mol Psychiatry. 2002;7(S1 Suppl 1):S71-80.

5 Krystal JH, Sanacora G, Duman RS. Rapidacting glutamatergic antidepressants: the path to ketamine and beyond. Biol Psychiatry. 2013 Jun;73(12):1133-41.

6 Kashiwagi K, Masuko T, Nguyen CD, Kuno $\mathrm{T}$, Tanaka I, Igarashi K, et al. Channel blockers acting at $\mathrm{N}$-methyl-D-aspartate receptors: differential effects of mutations in the vestibule and ion channel pore. Mol Pharmacol. 2002 Mar;61(3):533-45.

7 Kotermanski SE, Johnson JW. Mg2+ imparts NMDA receptor subtype selectivity to the Alzheimer's drug memantine. J Neurosci. 2009 Mar;29(9):2774-9.

8 aan het Rot M, Collins KA, Murrough JW, Perez AM, Reich DL, Charney DS, et al. aan het Rot M, Collins KA, Murrough JW, Perez AM, Reich DL, Charney DS, Mathew SJ: safety and efficacy of repeated-dose intravenous ketamine for treatment-resistant depression. Biol Psychiatry. 2010;67(2):139-45.

9 Diazgranados N, Ibrahim L, Brutsche NE, Newberg A, Kronstein P, Khalife S, et al. A randomized add-on trial of an N-methyl-Daspartate antagonist in treatment-resistant bipolar depression. Arch Gen Psychiatry. 2010 Aug;67(8):793-802.

10 Larkin GL, Beautrais AL. A preliminary naturalistic study of low-dose ketamine for depression and suicide ideation in the emergency department. Int J Neuropsychopharmacol. 2011 Sep;14(8):1127-31.

11 Chatterjee M, Ganguly S, Srivastava M, Palit G. Effect of 'chronic' versus 'acute' ketamine administration and its 'withdrawal' effect on behavioural alterations in mice: implications for experimental psychosis. Behav Brain Res. 2011 Jan;216(1):247-54.
12 Chatterjee M, Verma R, Ganguly S, Palit G. Neurochemical and molecular characterization of ketamine-induced experimental psychosis model in mice. Neuropharmacology. 2012 Nov;63(6):1161-71.

13 Cilia J, Hatcher P, Reavill C, Jones DN. (+/-) Ketamine-induced prepulse inhibition deficits of an acoustic startle response in rats are not reversed by antipsychotics. J Psychopharmacol. 2007 May;21(3):302-11.

14 McEntee WJ, Crook TH. Glutamate: its role in learning, memory, and the aging brain. Psychopharmacology (Berl). 1993;111(4): 391-401.

15 Pessoa L. On the relationship between emotion and cognition. Nat Rev Neurosci. 2008 Feb;9(2):148-58.

16 Holtmaat A, Svoboda K. Experience-dependent structural synaptic plasticity in the mammalian brain. Nat Rev Neurosci. 2009 Sep;10(9):647-58.

17 Whitlock JR, Heynen AJ, Shuler MG, Bear MF. Learning induces long-term potentiation in the hippocampus. Science. 2006 Aug; 313(5790):1093-7.

18 Li N, Lee B, Liu RJ, Banasr M, Dwyer JM, Iwata $\mathrm{M}$, et al. mTOR-dependent synapse formation underlies the rapid antidepressant effects of NMDA antagonists. Science. 2010 Aug; 329(5994):959-64.

19 Zanos P, Moaddel R, Morris PJ, Georgiou P, Fischell J, Elmer GI, et al. NMDAR inhibition-independent antidepressant actions of ketamine metabolites. Nature. 2016 May; 533(7604):481-6

20 Autry AE, Adachi M, Nosyreva E, Na ES, Los MF, Cheng PF, et al. NMDA receptor blockade at rest triggers rapid behavioural antidepressant responses. Nature. 2011 Jun; 475(7354):91-5.

21 Moghaddam B, Adams B, Verma A, Daly D. Activation of glutamatergic neurotransmission by ketamine: a novel step in the pathway from NMDA receptor blockade to dopaminergic and cognitive disruptions associated with the prefrontal cortex. J Neurosci. 1997 Apr;17(8):2921-7.

22 Kessler RC. The effects of stressful life events on depression. Annu Rev Psychol. 1997; 48(1):191-214.

23 Thomas RM, Hotsenpiller G, Peterson DA. Acute psychosocial stress reduces cell survival in adult hippocampal neurogenesis without altering proliferation. J Neurosci. 2007 Mar; 27(11):2734-43.
24 Malberg JE, Duman RS. Cell proliferation in adult hippocampus is decreased by inescapable stress: reversal by fluoxetine treatment. Neuropsychopharmacology. 2003 Sep;28(9): 1562-71.

25 Pham K, Nacher J, Hof PR, McEwen BS. Repeated restraint stress suppresses neurogenesis and induces biphasic PSA-NCAM expression in the adult rat dentate gyrus. Eur J Neurosci. $2003 \mathrm{Feb}$;17(4):879-86.

26 Vermetten E, Bremner JD. Circuits and systems in stress. II. Applications to neurobiology and treatment in posttraumatic stress disorder. Depress Anxiety. 2002;16(1):14-38.

27 Koolschijn PC, van Haren NE, Lensvelt-Mulders GJ, Hulshoff Pol HE, Kahn RS. Brain volume abnormalities in major depressive disorder: a meta-analysis of magnetic resonance imaging studies. Hum Brain Mapp. 2009 Nov; 30(11):3719-35.

28 Kempton MJ, Salvador Z, Munafò MR, Geddes JR, Simmons A, Frangou S, et al. Structural neuroimaging studies in major depressive disorder. Meta-analysis and comparison with bipolar disorder. Arch Gen Psychiatry. 2011 Jul;68(7):675-90.

29 Arnone D, McIntosh AM, Ebmeier KP, Munafò MR, Anderson IM. Magnetic resonance imaging studies in unipolar depression: systematic review and meta-regression analyses. Eur Neuropsychopharmacol. 2012 Jan;22(1): $1-16$.

30 McEwen BS, Magarinos AM. Stress and hippocampal plasticity: implications for the pathophysiology of affective disorders. Hum Psychopharmacol. 2001 Jan;16 S1:S7-19.

31 Reagan LP, McEwen BS. Controversies surrounding glucocorticoid-mediated cell death in the hippocampus. J Chem Neuroanat. 1997 Aug; 13(3):149-67.

32 Cameron HA, Tanapat P, Gould E. Adrenal steroids and $\mathrm{N}$-methyl-D-aspartate receptor activation regulate neurogenesis in the dentate gyrus of adult rats through a common pathway. Neuroscience. 1998 Jan;82(2):34954.

33 Rajkowska G. Postmortem studies in mood disorders indicate altered numbers of neurons and glial cells. Biol Psychiatry. 2000 Oct; 48(8):766-77.

34 Zakzanis KK, Leach L, Kaplan E. On the nature and pattern of neurocognitive function in major depressive disorder. Neuropsychiatry Neuropsychol Behav Neurol. 1998 Jul; 11(3):111-9. 
35 Frodl T, Bokde AL, Scheuerecker J, Lisiecka D, Schoepf V, Hampel H, et al. Functional connectivity bias of the orbitofrontal cortex in drug-free patients with major depression. Biol Psychiatry. 2010 Jan;67(2):161-7.

36 Gutteridge A, Pir P, Castrillo JI, Charles PD, Lilley KS, Oliver SG. Nutrient control of eukaryote cell growth: a systems biology study in yeast. BMC Biol. 2010 May;8(1):68.

37 Yuan M, Breitkopf SB, Yang X, Asara JM. A positive/negative ion-switching, targeted mass spectrometry-based metabolomics platform for bodily fluids, cells, and fresh and fixed tissue. Nat Protoc. 2012 Apr;7(5):87281.

38 Xia J, Psychogios N, Young N, Wishart DS. MetaboAnalyst: a web server for metabolomic data analysis and interpretation. Nucleic Acids Res. 2009 Jul;37(Web Server issue): W652-60.

39 Wold S, Sjostrom M, Eriksson L. PLS-regression: a basic tool of chemometrics. Chemom Intell Lab Syst. 2001;58(2):109-30.

40 Weckmann K, Labermaier C, Asara JM, Müller MB, Turck CW. Time-dependent metabolomic profiling of Ketamine drug action reveals hippocampal pathway alterations and biomarker candidates. Transl Psychiatry. 2014 Nov;4(11):e481.

41 Bear MF, Connors BW, Paradiso MA. Neurowissenschaften: Ein grundlegendes Lehrbuch für Biologie. Medizin und Psychologie; 2009.
42 Isaac JT, Ashby MC, McBain CJ. The role of the GluR2 subunit in AMPA receptor function and synaptic plasticity. Neuron. 2007 Jun;54(6):859-71.

43 Turrigiano GG, Leslie KR, Desai NS, Rutherford LC, Nelson SB. Activity-dependent scaling of quantal amplitude in neocortical neurons. Nature. 1998 Feb;391(6670):892-6.

44 Turrigiano GG, Nelson SB. Thinking globally, acting locally: AMPA receptor turnover and synaptic strength. Neuron. 1998 Nov;21(5): 933-5.

45 Turrigiano GG, Nelson SB. Homeostatic plasticity in the developing nervous system. Nat Rev Neurosci. 2004 Feb;5(2):97-107.

46 Guidotti A, Corda MG, Wise BC, Vaccarino F, Costa E. GABAergic synapses. Supramolecular organization and biochemical regulation. Neuropharmacology. 1983 Dec;22(12 12B):1471-9.

47 Peng L, Hertz L, Huang R, Sonnewald U, Petersen $\mathrm{SB}$, Westergaard $\mathrm{N}$, et al. Utilization of glutamine and of TCA cycle constituents as precursors for transmitter glutamate and GABA. Dev Neurosci. 1993;15(3-5):367-77.

48 Schousboe A, Westergaard N, Sonnewald U, Petersen SB, Huang R, Peng L, et al. Glutamate and glutamine metabolism and compartmentation in astrocytes. Dev Neurosci. 1993;15(3-5):359-66.
49 Zomkowski AD, Santos AR, Rodrigues AL. Putrescine produces antidepressant-like effects in the forced swimming test and in the tail suspension test in mice. Prog Neuropsychopharmacol Biol Psychiatry. 2006 Dec; 30(8):1419-25.

50 MacQueen G, Frodl T. The hippocampus in major depression: evidence for the convergence of the bench and bedside in psychiatric research? Mol Psychiatry. 2011 Mar;16(3): 252-64.

51 McEwen BS. The ever-changing brain: cellular and molecular mechanisms for the effects of stressful experiences. Dev Neurobiol. 2012 Jun;72(6):878-90.

52 Banasr M, Dwyer JM, Duman RS. Cell atrophy and loss in depression: reversal by antidepressant treatment. Curr Opin Cell Biol. 2011 Dec;23(6):730-7.

53 Pittenger C, Duman RS. Stress, depression, and neuroplasticity: a convergence of mechanisms. Neuropsychopharmacology. 2008 Jan; 33(1):88-109.

54 Wood GE, Young LT, Reagan LP, Chen B, McEwen BS. Stress-induced structural remodeling in hippocampus: prevention by lithium treatment. Proc Natl Acad Sci USA. 2004 Mar;101(11):3973-8.

55 Swerdlow NR, Taaid N, Oostwegel JL, Randolph E, Geyer MA. Towards a cross-species pharmacology of sensorimotor gating: effects of amantadine, bromocriptine, pergolide and ropinirole on prepulse inhibition of acoustic startle in rats. Behav Pharmacol. 1998 Sep; 9(5-6):389-96. 